\title{
6-Halopyridylmethylidene penicillin-based sulfones efficiently inactivate the natural resistance of Pseudomonas aeruginosa to $\beta$-lactam antibiotics
}

Juan C. Vázquez-Ucha, ${ }^{\# a}$ Diana Rodríguez, ${ }^{\# b}$ Cristina Lasarte-Monterrubio, ${ }^{\# a}$ Emilio Lence, ${ }^{b}$ Jorge ArcaSuarez, ${ }^{a}$ María Maneiro, ${ }^{b}$ Eva Gato, ${ }^{a}$ Astrid Perez, ${ }^{a}$ Marta Martínez-Guitián, ${ }^{a}$ Carlos Juan, ${ }^{c}$ Antonio Oliver, ${ }^{c}$ German Bou, ${ }^{a}$ Concepción González-Bello, ${ }^{* \pm b}$ and Alejandro Beceiro ${ }^{* \pm a}$

${ }^{a}$ Servicio de Microbiología do Complejo Hospitalario Universitario da Coruña (CHUAC), Instituto de Investigación Biomédica da Coruña (CICA-INIBIC), Xubias de Arriba, 84, 15006 A Coruña, Spain.

${ }^{\mathrm{b}}$ Centro Singular de Investigación en Química Biolóxica e Materiais Moleculares (CiQUS), Departamento de Química Orgánica, Universidade de Santiago de Compostela, Jenaro de la Fuente s/n, 15782 Santiago de Compostela, Spain.

'Servicio de Microbiología y Unidad de Investigación, Hospital Universitario Son Espases, Instituto de Investigación Sanitaria Illes Balears (IdiSBA), Carretera de Valldemossa, 79, 07120, Palma de Mallorca, Spain.

Table of Contents

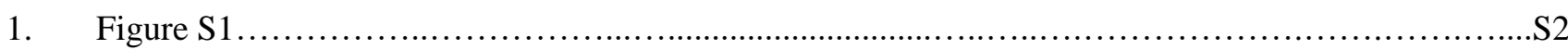

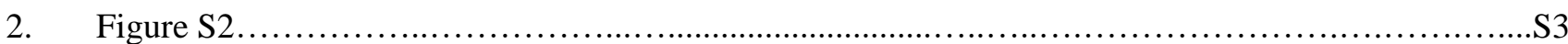

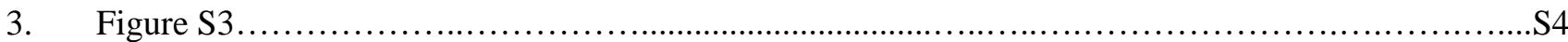

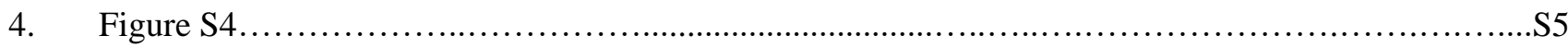

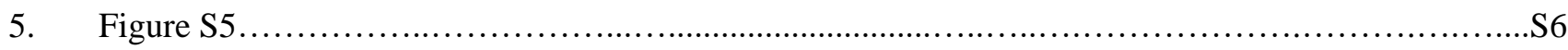

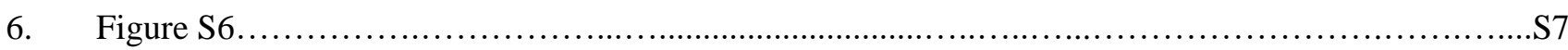

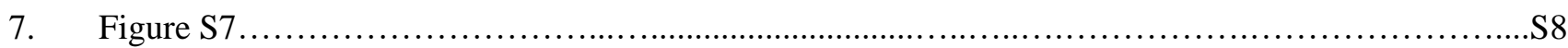

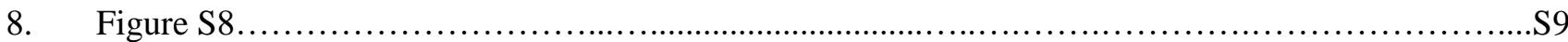

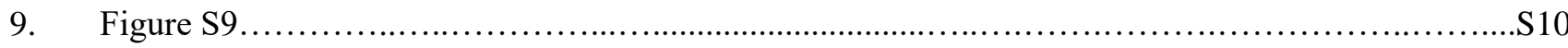

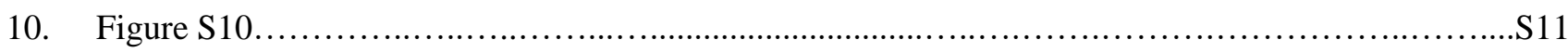

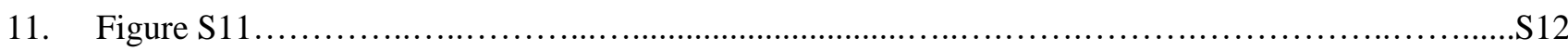

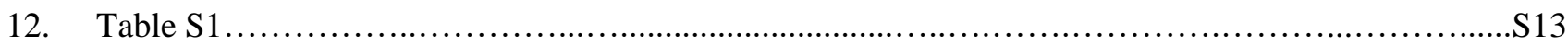

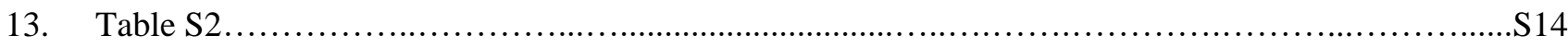

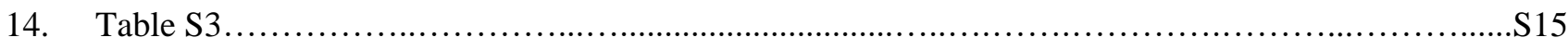

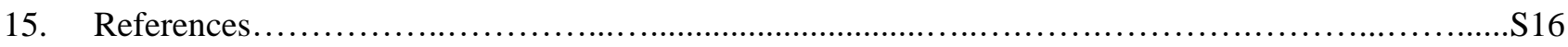


A

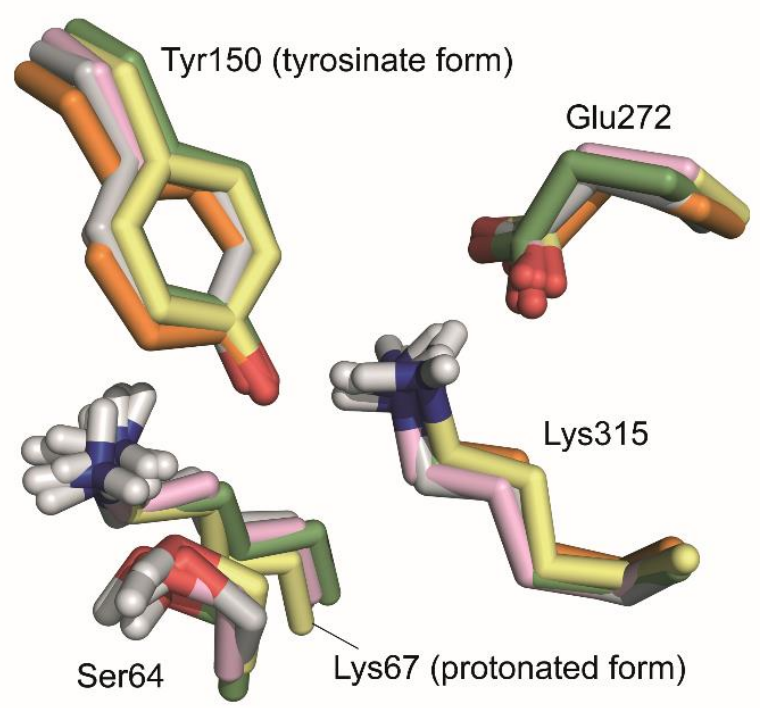

C

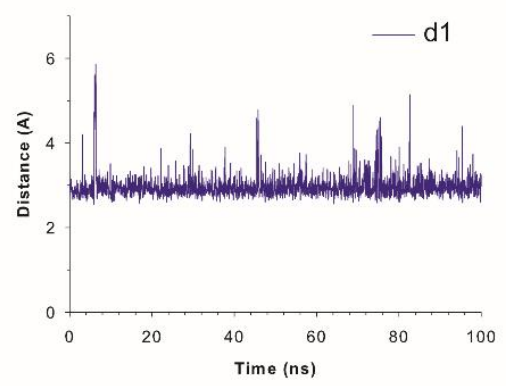

B

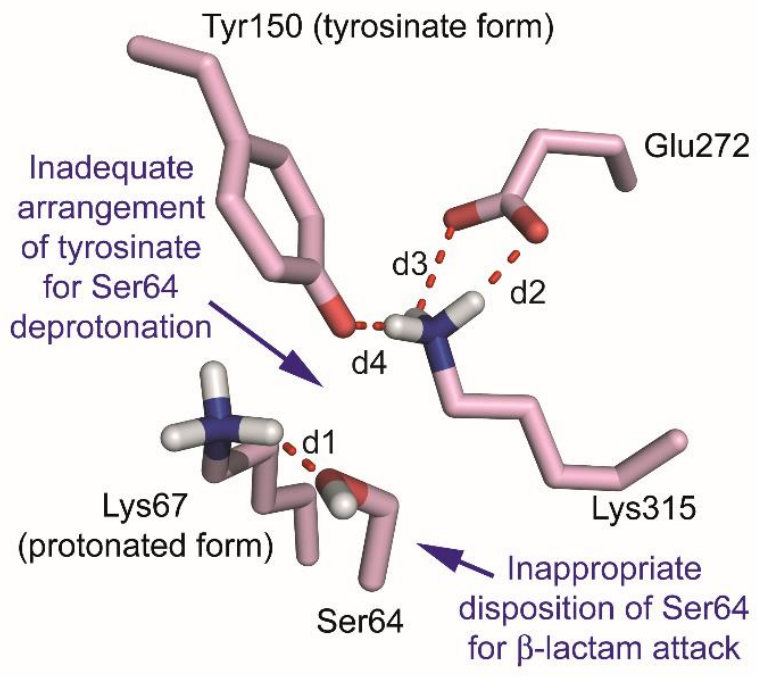

$\mathrm{E}$

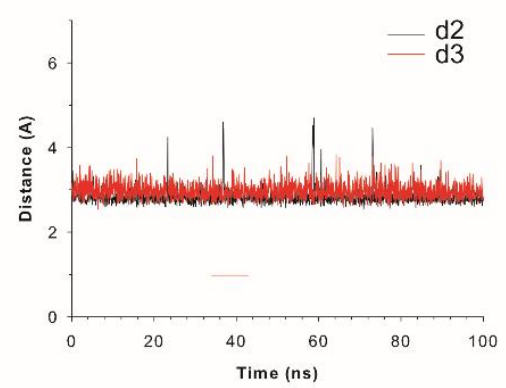

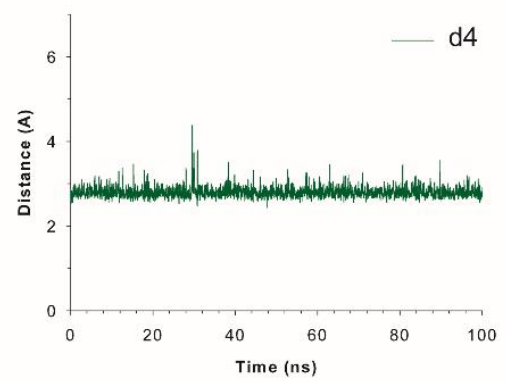

Figure S1. A. Comparison of several snapshots of the unbound form of PDC-1 during 100 ns of MD simulation, in which the ionic forms of residues Tyr150 (tyrosinate) and Lys67 (protonated) were considered. Relevant side chain residues of the active site are shown and labeled. B. Snapshot after $80 \mathrm{~ns}$ of simulation is shown. Relevant polar contacts are provided as red dashed lines. C-E. Variation of the relative distance between: (C) the $\mathrm{OH}$ group (OG atom) of catalytic Ser64 and the nitrogen atom (NZ) of Lys67 (d1 in panel B); (D) the oxygen atoms (OE1 and OE2) of Glu272 and the nitrogen atom (NZ) of Lys315 (d2 and d3 in panel B); and the oxygen atom (OH) of Tyr150 and the nitrogen atom (NZ) of Lys315 (d4 in panel B); in the unbound form of PDC-1 during simulation. Note how both Tyr150 and Ser64 did not achieve the appropriate arrangement for the formation of the enzyme-acyl adduct. 
A

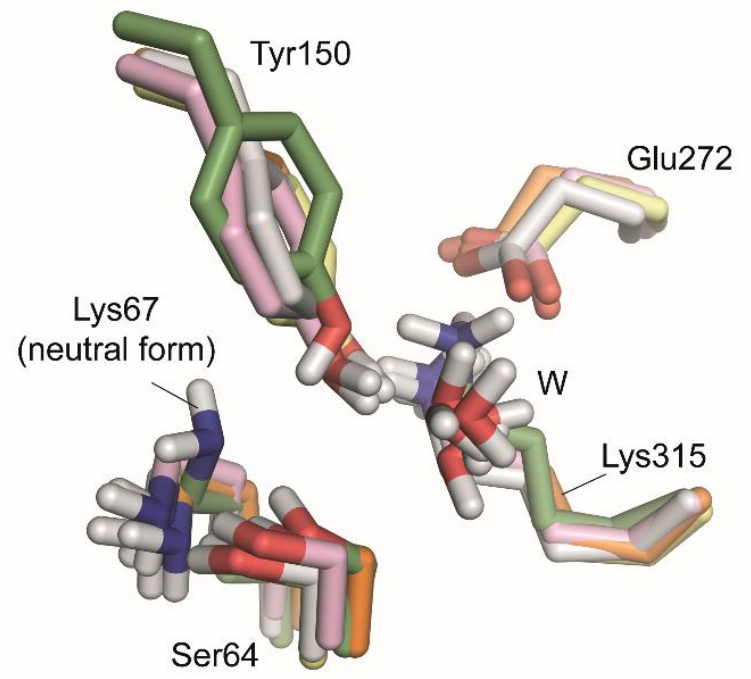

C

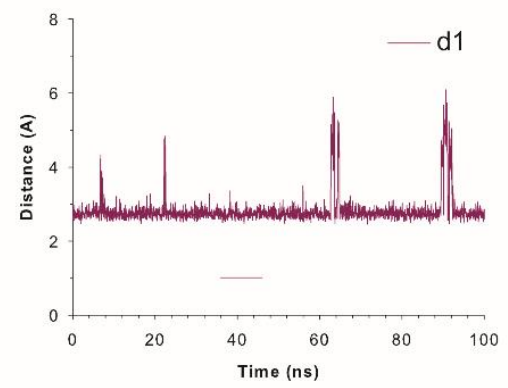

D
B

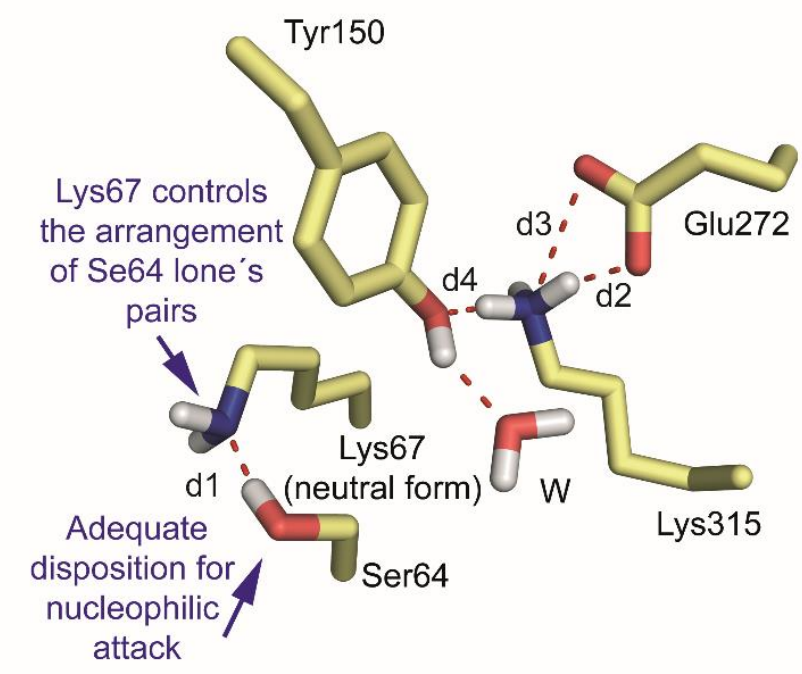

E

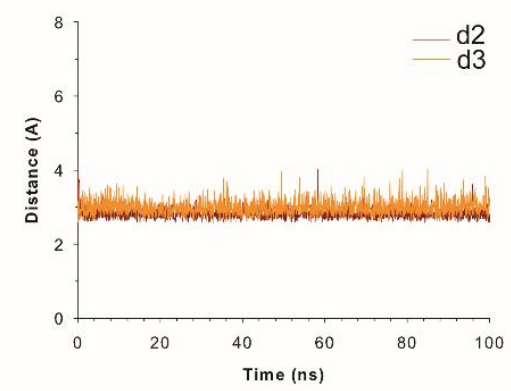

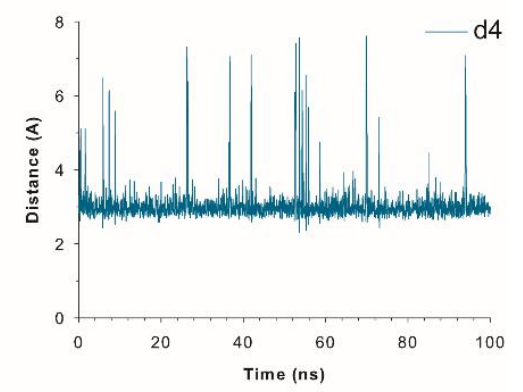

Figure S2. A. Comparison of several snapshots of the unbound form of PDC-1 during $100 \mathrm{~ns}$ of MD simulation, in which the neutral forms of the residues Tyr150 and Lys67 were considered. Relevant side chain residues of the active site are shown and labeled. B. Snapshot after $80 \mathrm{~ns}$ of simulation is shown. Relevant polar contacts are provided as red dashed lines. C-E. Variation of the relative distance between: (C) the $\mathrm{OH}$ group (OG) of catalytic Ser64 and the nitrogen atom (NZ) of Lys67 (d1 in panel B); (D) the oxygen atoms (OE1 and OE2) of Glu272 and the nitrogen atom (NZ) of Lys315 (d2 and d3 in panel B); and the oxygen atom $(\mathrm{OH})$ of Tyr150 and the nitrogen atom (NZ) of Lys315 (d4 in panel B); in the unbound form of PDC-1 during simulation. Note how Lys67 and Ser64 would have the appropriate arrangement for the formation of the enzyme-acyl adduct, in which Lys67 would control the appropriate arrangement of the lone pairs of Ser64 for nucleophilic attack. 


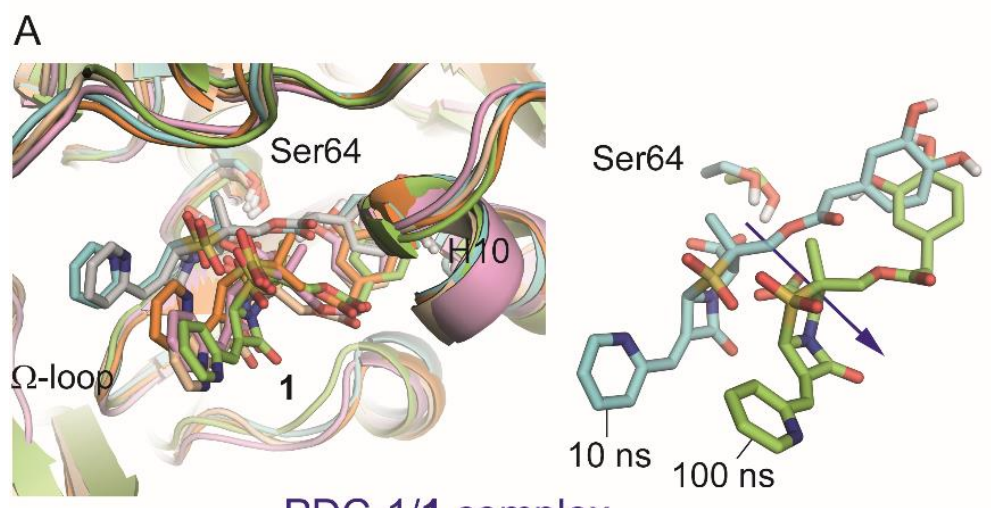

B

PDC-1/1 complex
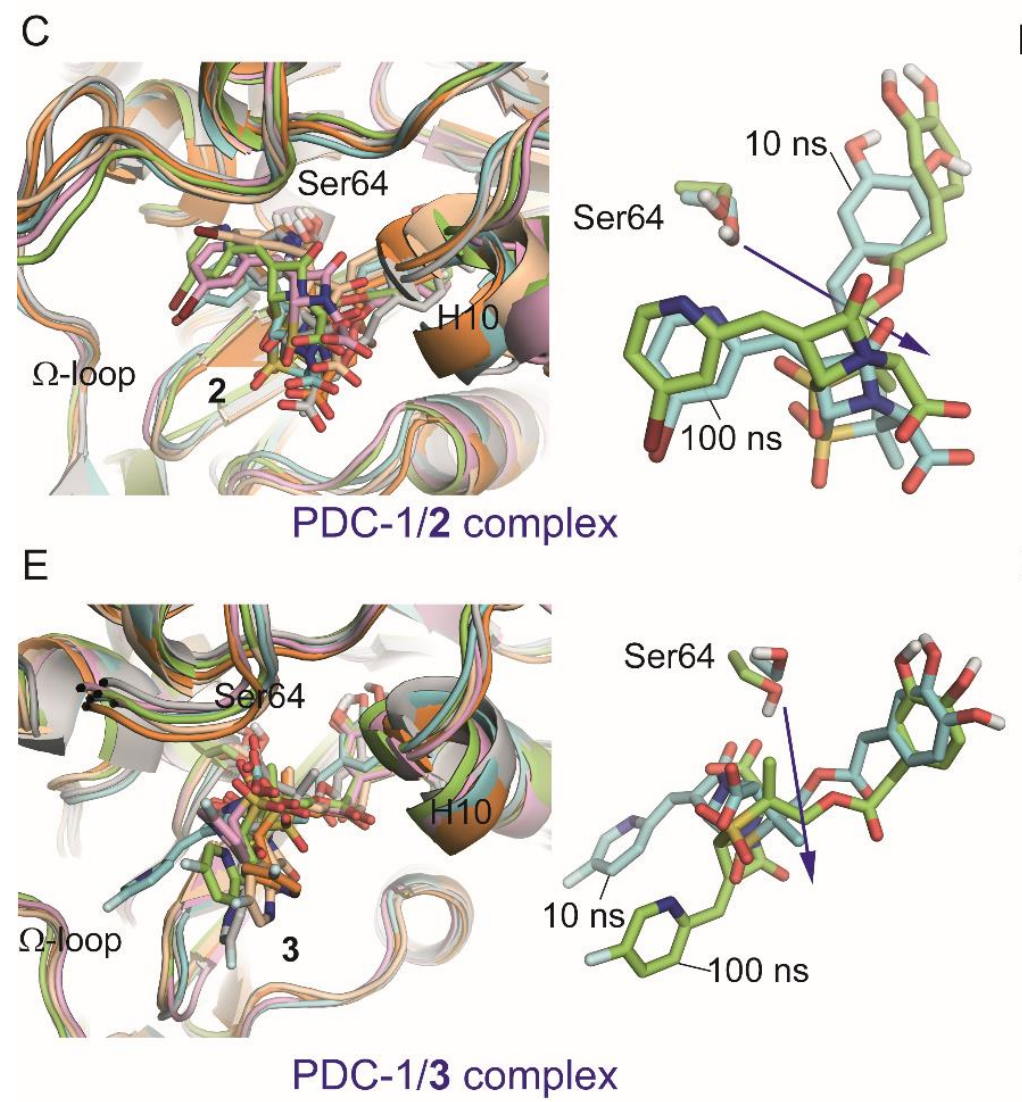

$\mathrm{F}$

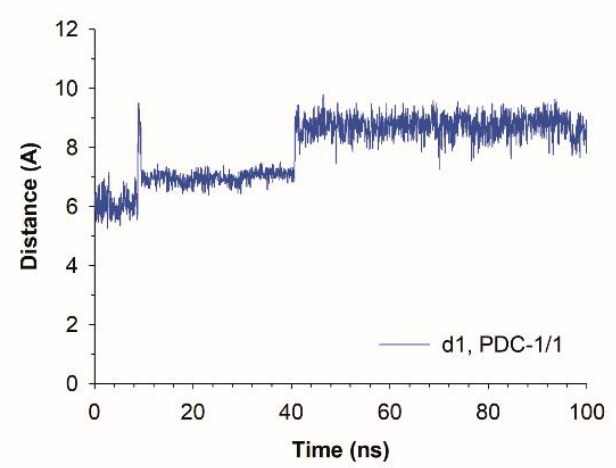

D
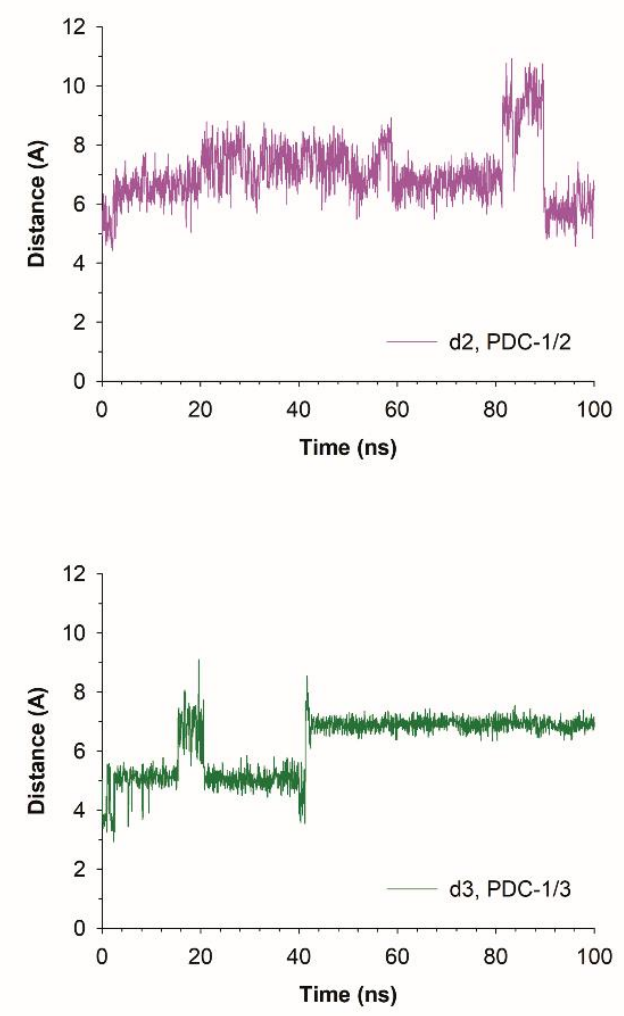

$10 \mathrm{~ns} 30 \mathrm{~ns} 50 \mathrm{~ns} 70 \mathrm{~ns} \bigcirc 90 \mathrm{~ns} 100 \mathrm{~ns}$

Figure S3. MD simulation studies on the possible arrangement of the inhibitors $\mathbf{1}-\mathbf{3}$ in the PDC-1 active site in which their siderophore (catechol) group would be located on the pocket formed by the H10 helix, and the pyridylmethylidene group in the vicinity of the $\Omega$-loop. A, C, E Comparison of several snapshots of the PDC1/1 (A), PDC-1/2 (C) and PDC-1/3 (E) binary enzyme complexes during $100 \mathrm{~ns}$ of MD simulations are shown. B, D, F Variation of the relative distance between the OH group of Ser64 (OG atom) and the carbonyl group (carbon atom) of ligands $\mathbf{1}$ (B), 2 (D) and $\mathbf{3}$ (F) in the corresponding PDC-1/1-3 enzyme complexes during the simulation. Note how all the inhibitors moved away from the OH group of Ser64 (OG atom) up to $10 \AA$ and the disposition is not appropriate for the nucleophilic attack. 
A

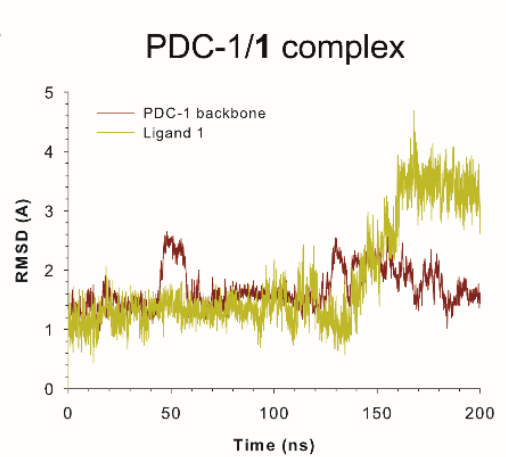

D

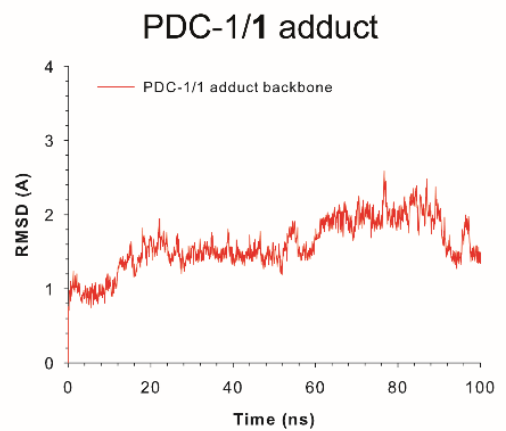

B

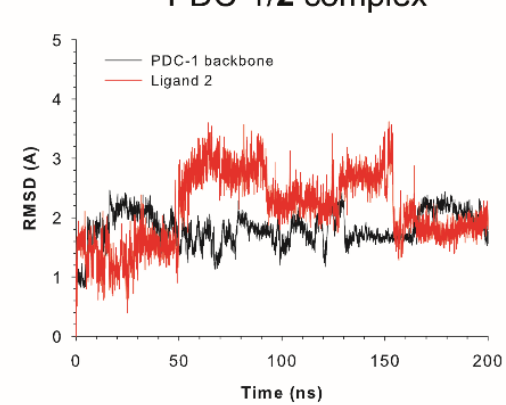

$\mathrm{E}$

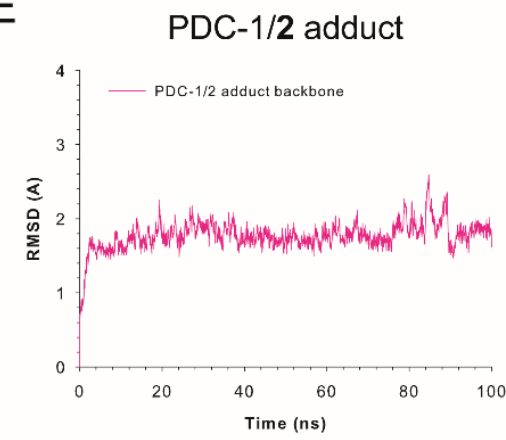

C PDC-1/3 complex

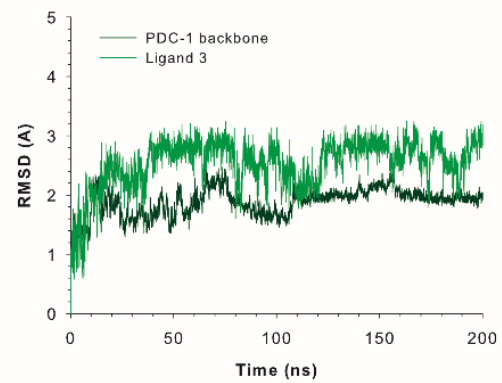

$\mathrm{F}$ PDC- $1 / 3$ adduct

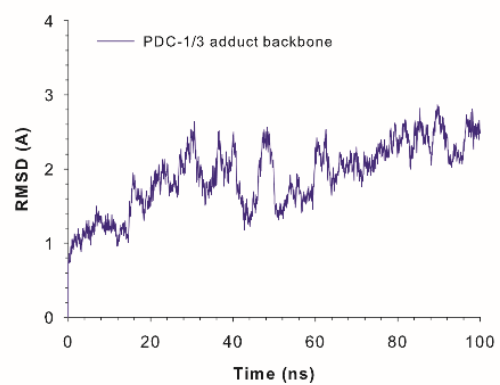

Figure S4. RMSD (Root-mean-square deviation) plots for the protein backbone ( $\mathrm{C} \alpha, \mathrm{C}, \mathrm{N}$, and $\mathrm{O}$ atoms) and ligands $\mathbf{1}-\mathbf{3}$ in the PDC-1/1-3 enzyme complexes (A-C) and PDC-1/1-3 enzyme adducts (D-F) obtained from MD simulations studies. For all cases, the RMSD values for the enzyme backbone are very low with average values ranging from $1.7 \AA$ and $1.9 \AA$ for complexes and from $1.6 \AA$ and $1.9 \AA$ for adducts. Similarly, the average RMSD values for the ligands in the enzyme complexes range from $1.8 \AA$ and $2.5 \AA$, which are also low considering the large flexibility of the siderophore side chain. 
A

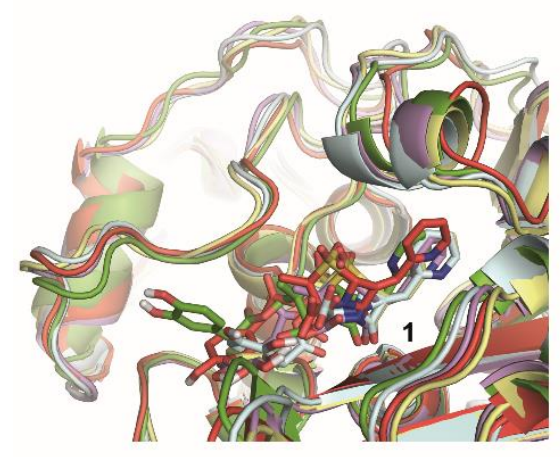

D

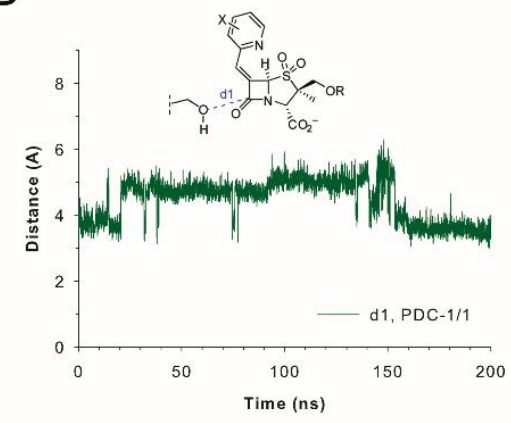

B

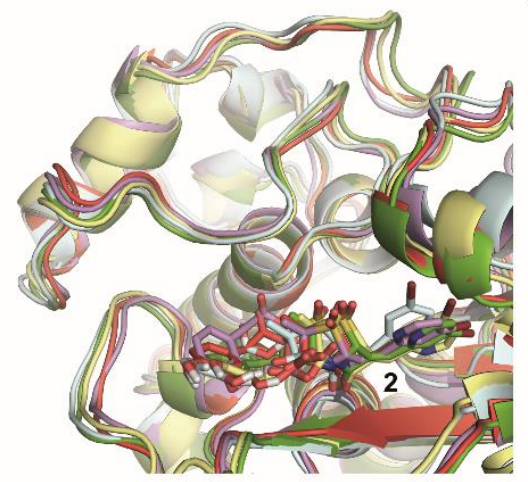

$\mathrm{E}$

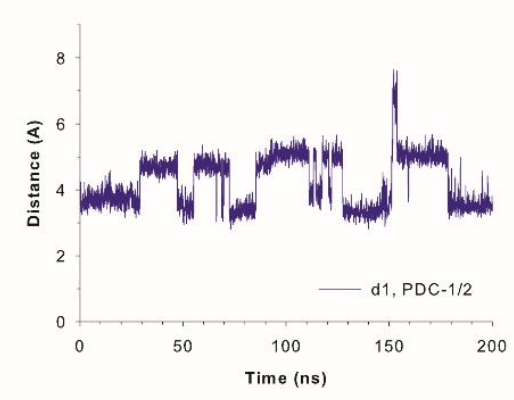

C

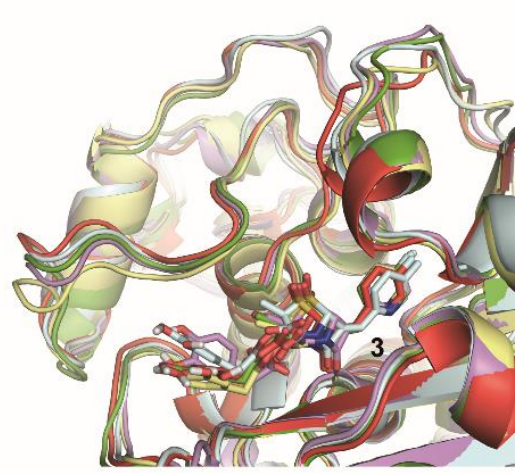

$\mathrm{F}$

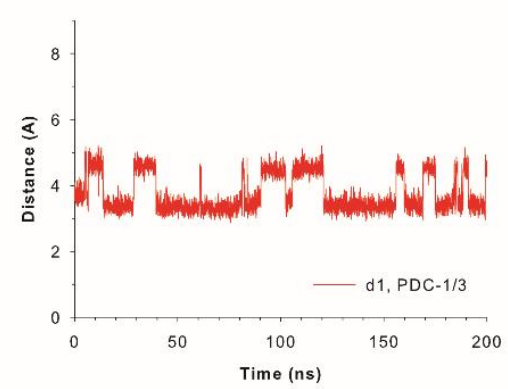

Figure S5. A-C. Comparison of several snapshots of the PDC-1/1 (A), PDC-1/2 (B) and PDC-1/3 (C) binary enzyme complexes during $200 \mathrm{~ns}$ of MD simulations. The ligands are shown as sticks. Note how inhibitor 1 showed higher mobility than compounds 2-3 within the pocket. D-F. Variation of the relative distance between the $\mathrm{OH}$ group of Ser64 (OG atom) and the carbonyl group (carbon atom) of ligands 1 (D), 2 (E) and $3(F)$ in the corresponding PDC-1/1-3 enzyme complexes during the simulation. The average distance during the whole simulation were $4.5 \AA$ (D), $4.2 \AA$ (E) and $3.7 \AA$ (F). Note how ligands 2 and 3 are closer to the nucleophilic Ser64 during a higher percentage of the simulation. 


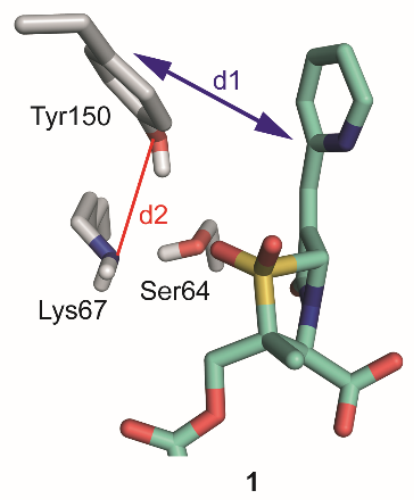

A

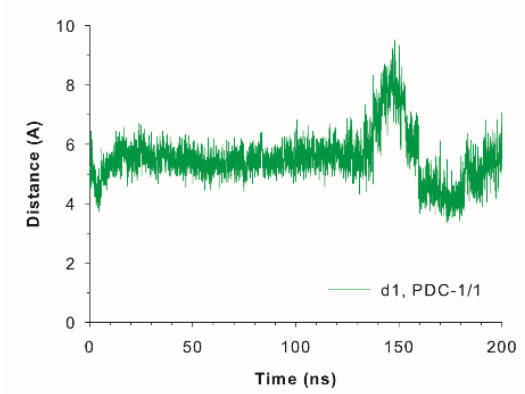

$\mathrm{D}$

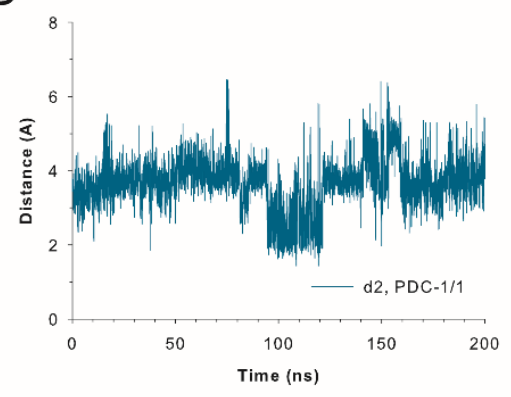

G

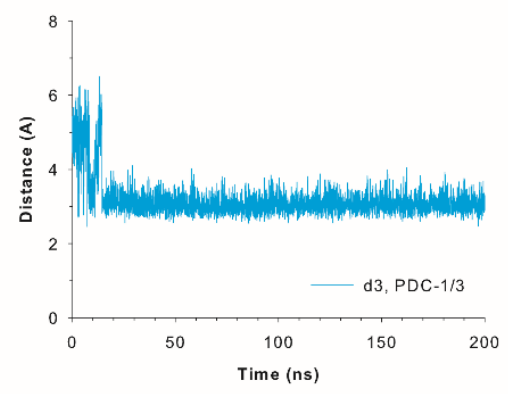

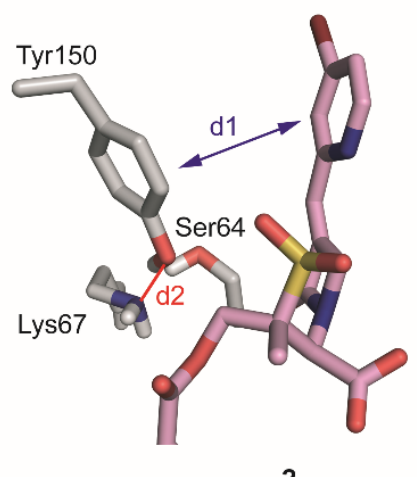

B

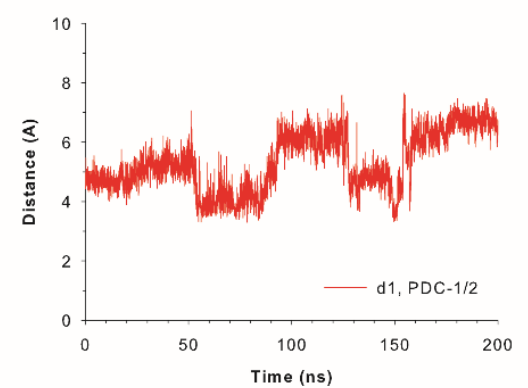

$\mathrm{E}$

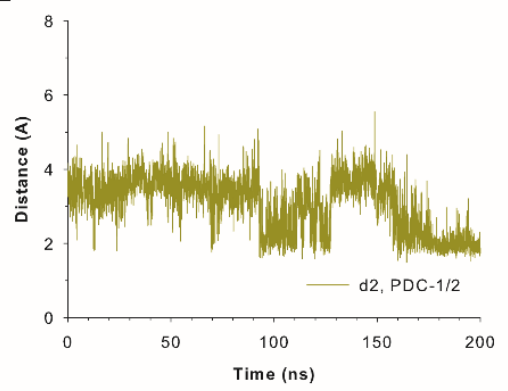

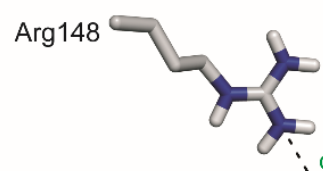

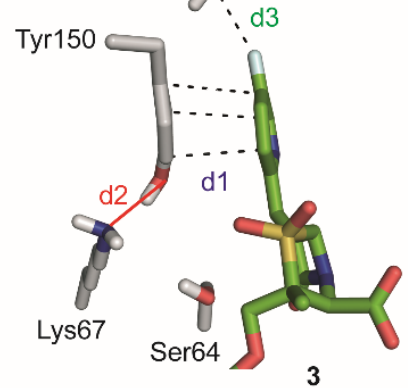

C

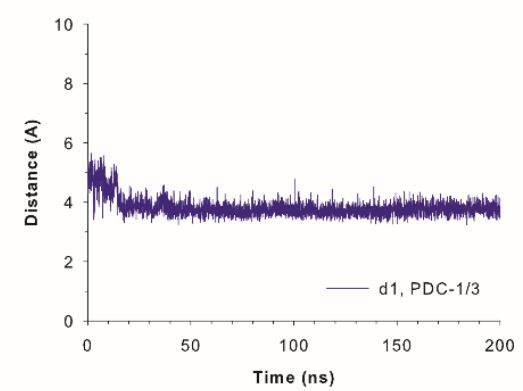

$\mathrm{F}$

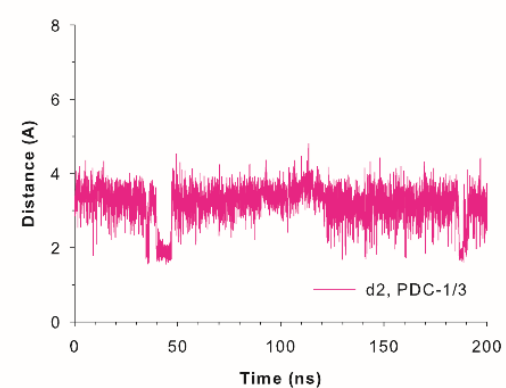

Figure S6. A-C. Variation of the relative distance between the mass centers of the phenol group of Tyr150 and the pyridyl moiety in 1-3 in the corresponding PDC-1/1-3 enzyme complexes during simulation [average distances were $5.5 \AA, 5.3 \AA$ and $3.8 \AA$, respectively]. D-F. Variation of the relative distance between the NZ atom of Lys67 and the $\mathrm{OH}$ group (HH atom) of Tyr150 in the PDC-1/1-3 enzyme during the whole simulation [average distances were $3.7 \AA$, $3.1 \AA$ and $3.2 \AA$, respectively]. G. Variation of the relative distance between the fluorine substituent in $\mathbf{3}$ and the nitrogen atom (NH2) of the guanidinium group of $\operatorname{Arg} 148$ in the PDC-1/3 enzyme complex during whole simulation [average distance was $3.2 \AA$ ] . 
A

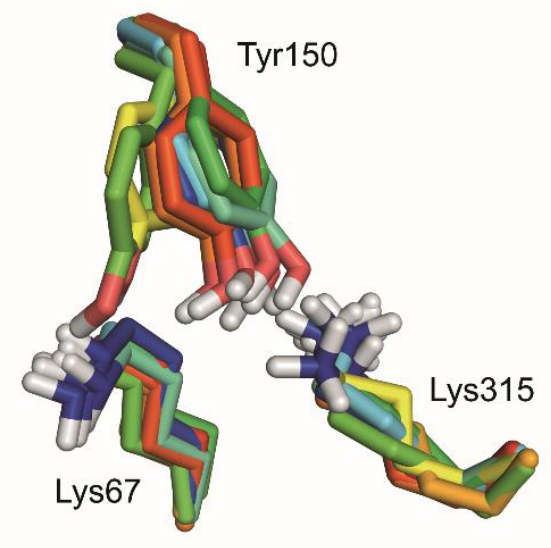

PDC-1/1
B

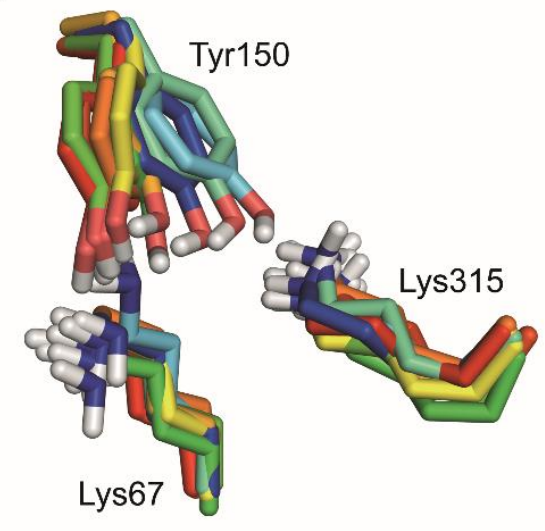

PDC-1/2
C

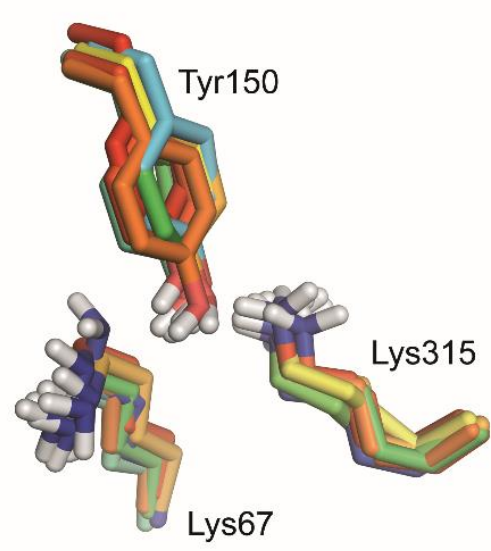

PDC-1/3

Figure S7. Comparison of the relative positions of the side chains of the Lys-Tyr-Lys triad (Lys67-Tyr150Lys315) in several snapshots of the PDC-1/1 (A), PDC-1/2 (B) and PDC-1/3 (C) enzyme complexes obtained from MD simulations studies. Note how for the PDC-1/2-3 complexes, the side chain of Tyr177 would be during a higher percentage of the simulation in close contact with Lys67, while would be mainly further away in PDC-1/1. For the PDC-1/3 complex, the position of Tyr150 would be frozen, while a more flexible arrangement was observed for PDC-1/2. 

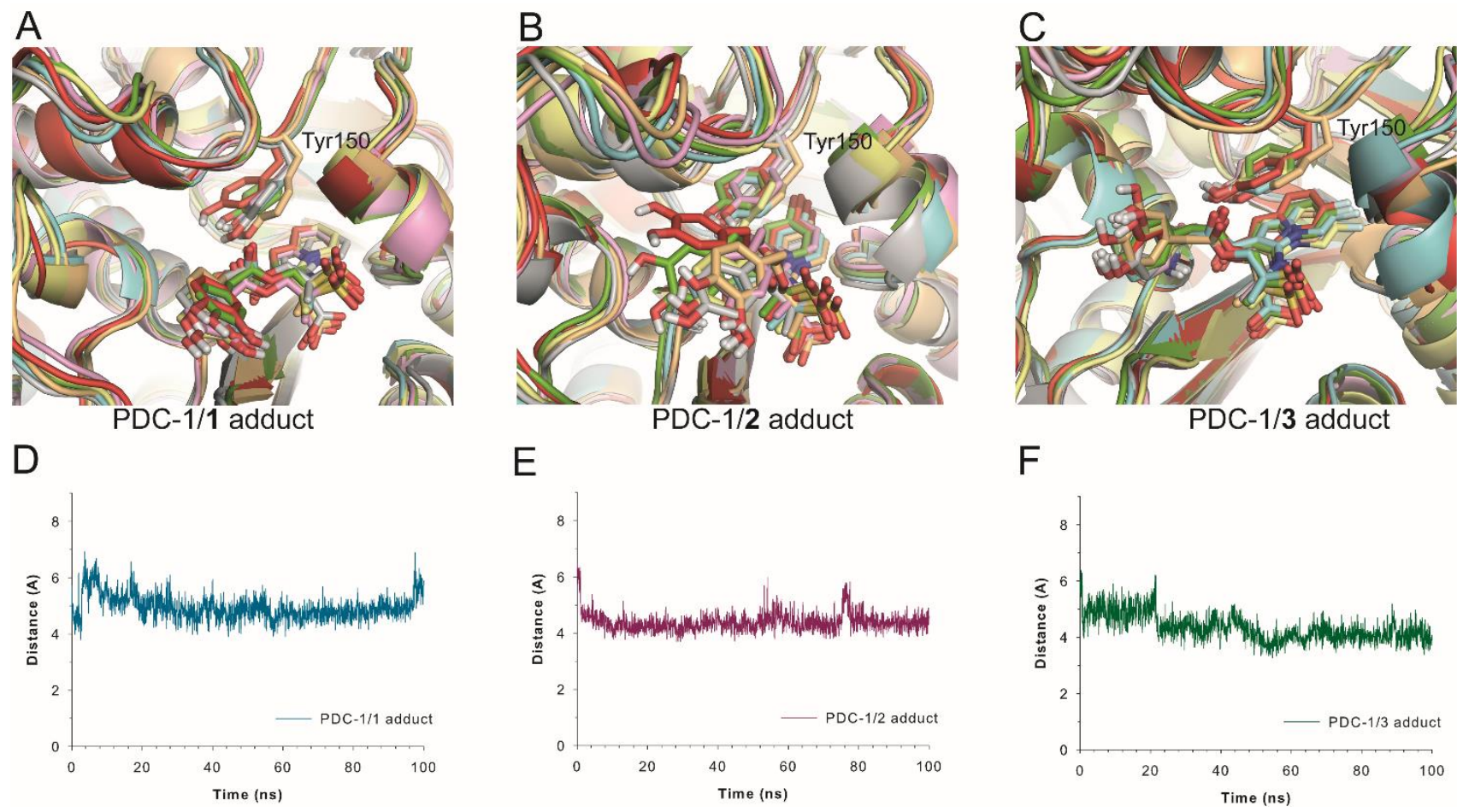

Figure S8. A-C. Comparison of several snapshots of the PDC-1/1 (A), PDC-1/2 (B) and PDC-1/3 (C) acyl enzyme adducts during $100 \mathrm{~ns}$ of MD simulation. The residues Tyr150 and the modified Ser64 are shown as sticks. D-F. Variation of the relative distance between the mass centers of the phenol group of Tyr150 and the pyridyl moiety in the corresponding PDC-1/1-3 acyl enzyme adducts during simulation. Note the relevant interaction between the indolizine moiety of modified ligands $\mathbf{2}$ and $\mathbf{3}$ and Tyr1750 that it is mainly absent for modified ligand $\mathbf{1}$. 


\section{Analysis Info}

Analysis Name

Method

D:IDatalCGIDRLILN1255_BB1_01_8202.d

Sample Name

8202.m

LN1255

Operator

Instrument

JLM

Comment

\section{Acquisition Parameter}

Ion Source Type ESI

Mass Range Mode UltraScan

Accumulation Time $\quad 37610 \mu \mathrm{s}$

SPS Target Mass

$500 \mathrm{~m} / \mathrm{z}$

$\begin{array}{ll}\text { Ion Polarity } & \text { Positive } \\ \text { Scan Begin } & 100 \mathrm{~m} / \mathrm{z} \\ \text { RF Level } & 71 \% \\ \text { Averages } & 8 \text { Spectra }\end{array}$

Alternating Ion Polarity

Scan End

Trap Drive

off

n/a

$2000 \mathrm{~m} / \mathrm{z}$

Averages

8 Spectra

LN1255 BB1_01_8202.d: UV Chromatogram, 270 nm

Intens.
[mAU]

600

600

(n)

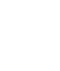

400

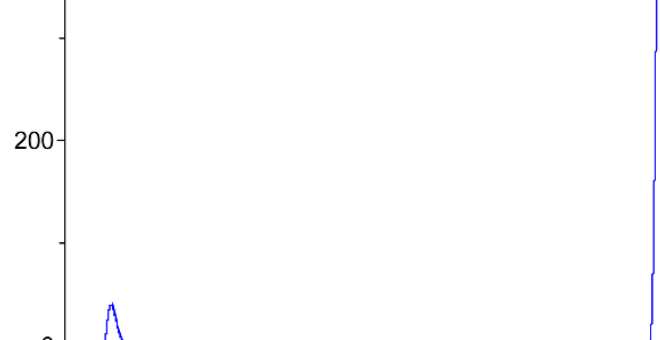

$0-$

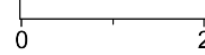

2

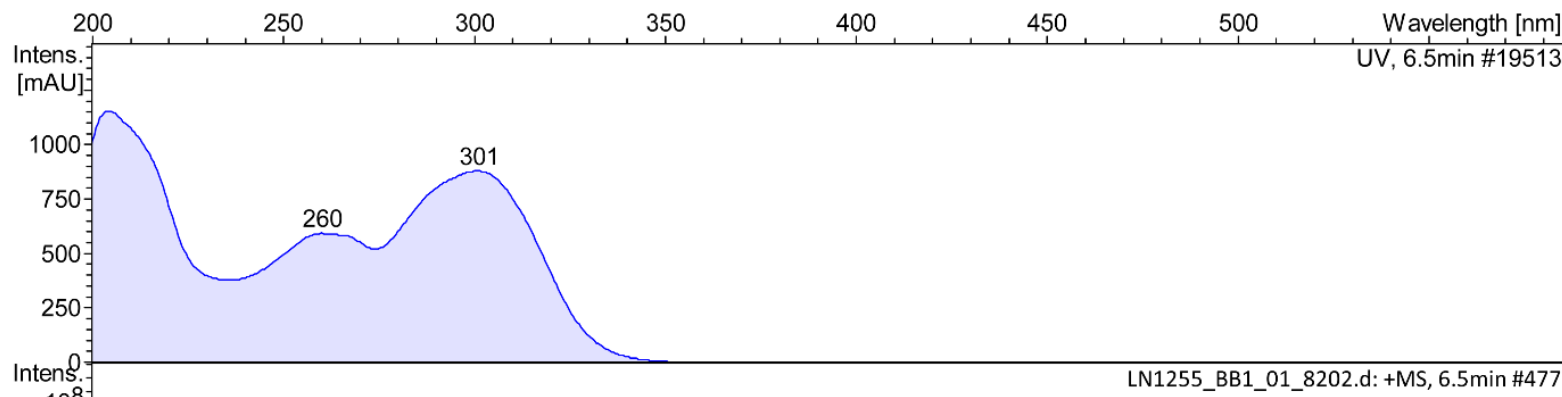

$\times 10^{8}$

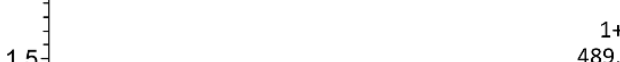

$1.5-1+$

$1.0-$

0.5

0.0

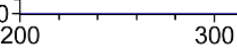

300

Bruker Compass DataAnalysis 4.2

by: JLM

Page 1 of 1

Figure S9. HPLC-MS purity analysis of compound $\mathbf{1}$. 


\section{Analysis Info}

Analysis Name

Method

'Data|CGIDRLIGB1DRL480 BB1 $018215 . d$

Sample Name

8215.m

GB1DRL480

Operator JLM

Instrument amaZon SL

Comment

Acquisition Parameter

\begin{tabular}{|c|c|c|c|c|c|}
\hline Ion Source Type & ESI & Ion Polarity & Positive & Alternating Ion Polarity & off \\
\hline Mass Range Mode & UltraScan & Scan Begin & $100 \mathrm{~m} / \mathrm{z}$ & Scan End & $2000 \mathrm{~m} / \mathrm{z}$ \\
\hline Accumulation Time & $31586 \mu \mathrm{s}$ & RF Level & $71 \%$ & Trap Drive & 53.6 \\
\hline SPS Target Mass & $500 \mathrm{~m} / \mathrm{z}$ & Averages & 8 Spectra & $\mathrm{n} / \mathrm{a}$ & $\mathrm{n} / \mathrm{a}$ \\
\hline
\end{tabular}
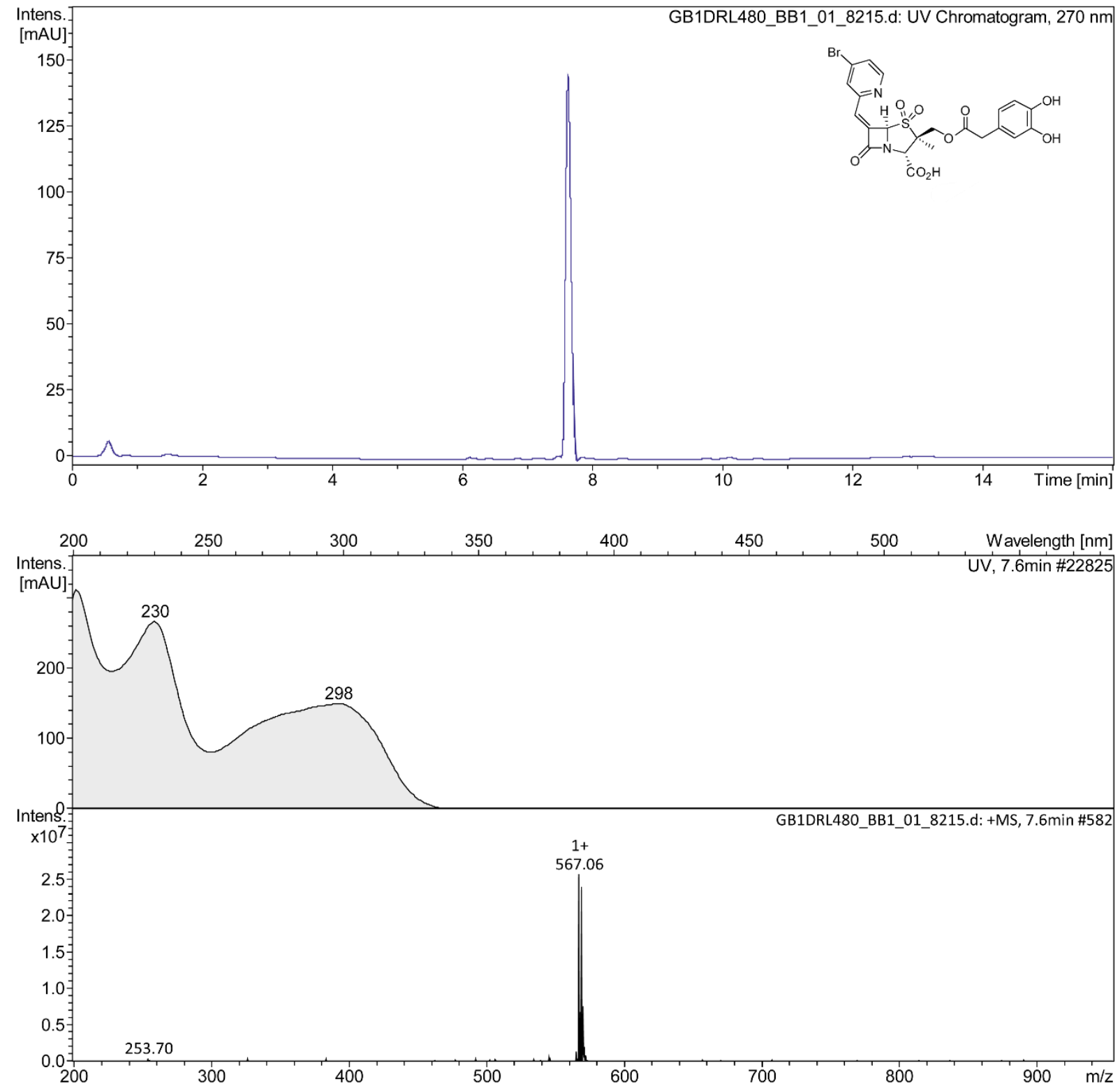

Bruker Compass DataAnalysis 4.2

by: JLM

Page 1 of 1

Figure S10. HPLC-MS purity analysis of compound 2. 
Analysis Info

Analysis Name

Method

D:|Data|CGIDRLIGB1DRL452_BB2_01_8217.d

Sample Name

8217.m

Operator

Instrument

JLM

GB1DRL452

amaZon SL

Comment

\section{Acquisition Parameter}

$\begin{array}{llllll}\text { Ion Source Type } & \text { ESI } & \text { Ion Polarity } & \text { Positive } & \text { Alternating lon Polarity } & \text { off } \\ \text { Mass Range Mode } & \text { UltraScan } & \text { Scan Begin } & 100 \mathrm{~m} / \mathrm{z} & \text { Scan End } & 2000 \mathrm{~m} / \mathrm{z} \\ \text { Accumulation Time } & 39409 \mu \mathrm{s} & \text { RF Level } & 71 \% & \text { Trap Drive } & 53.6 \\ \text { SPS Target Mass } & 500 \mathrm{~m} / \mathrm{z} & \text { Averages } & 8 \text { Spectra } & \text { n/a } & n / a\end{array}$

SPS Target Mass $\quad 500 \mathrm{~m} / \mathrm{z}$

Averages 8 Spectra
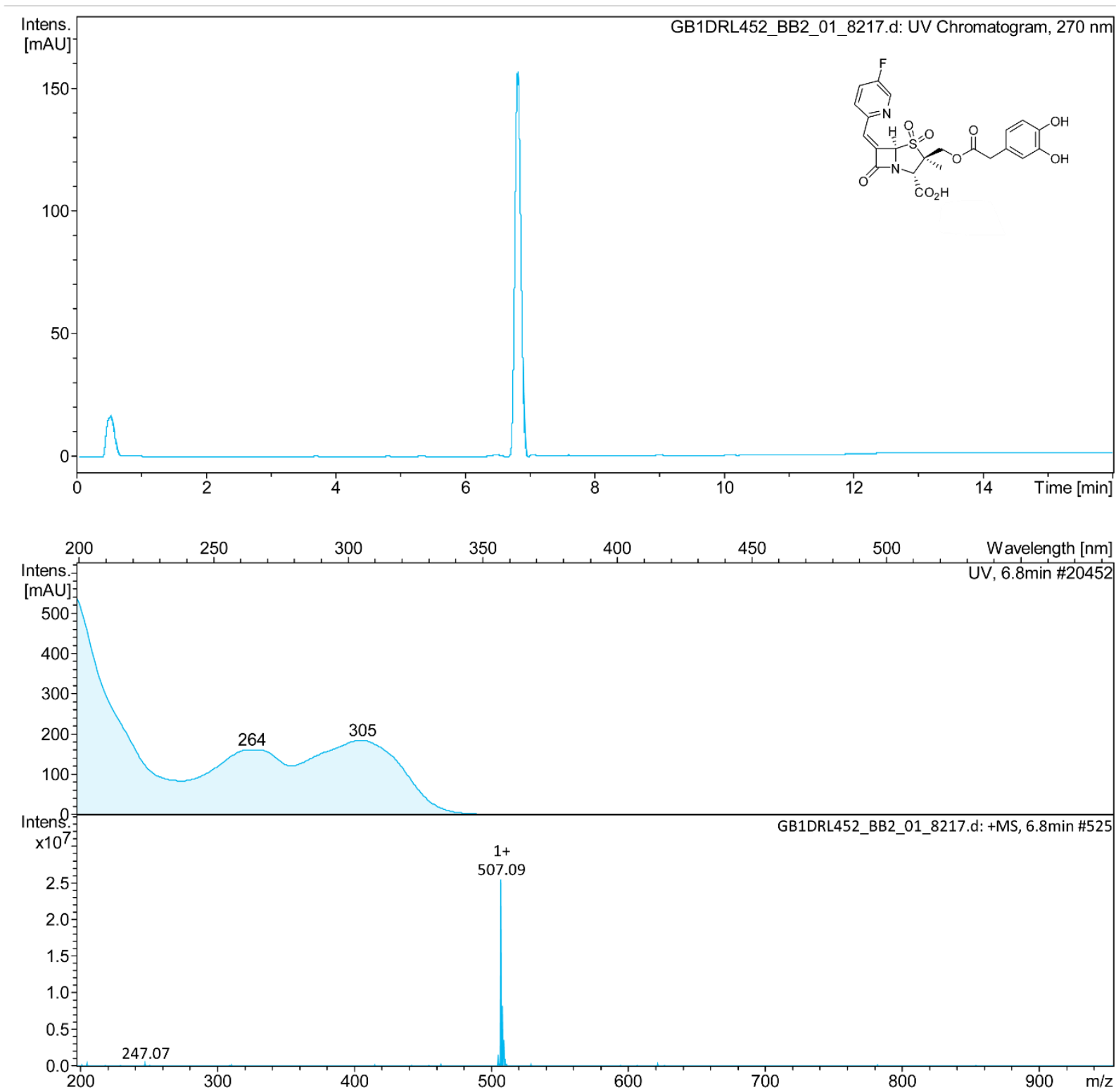

Bruker Compass DataAnalysis 4.2

by: JLM

Page 1 of 1

Figure S11. HPLC-MS purity analysis of compound 3 . 
Table S1. MIC values (mg/L) for ceftazidime with $P$. aeruginosa PAO1 $\triangle a m p D$, in the presence and absence of $\beta$-lactamase inhibitors 1-7 and avibactam.

\begin{tabular}{cc}
\hline Compounds & MIC (mg/L) \\
\hline No inhibitor & 8 \\
Avibactam & 1 \\
$\mathbf{1}$ & 1 \\
$\mathbf{2}$ & 1 \\
$\mathbf{3}$ & 1 \\
$\mathbf{4}$ & 2 \\
$\mathbf{5}$ & 2 \\
$\mathbf{6}$ & 1 \\
$\mathbf{7}$ & 8 \\
\hline
\end{tabular}


Table S2. MIC values (mg/L) for imipenem, ceftazidime and ampicillin with A. baumannii ATCC 17978, K. pneumoniae AompK 35/36 and E. coli TG1 pBGS18 carrying representative $\beta$-lactamases of classes D (OXA-23, OXA-24/40 and OXA-48), A (TEM-1 and CTX-M-2), and C (CMY-2 and DHA-1), in the presence and absence of $\beta$-lactamase inhibitors $\mathbf{1}-\mathbf{3}$, avibactam and relebactam. ${ }^{a}$

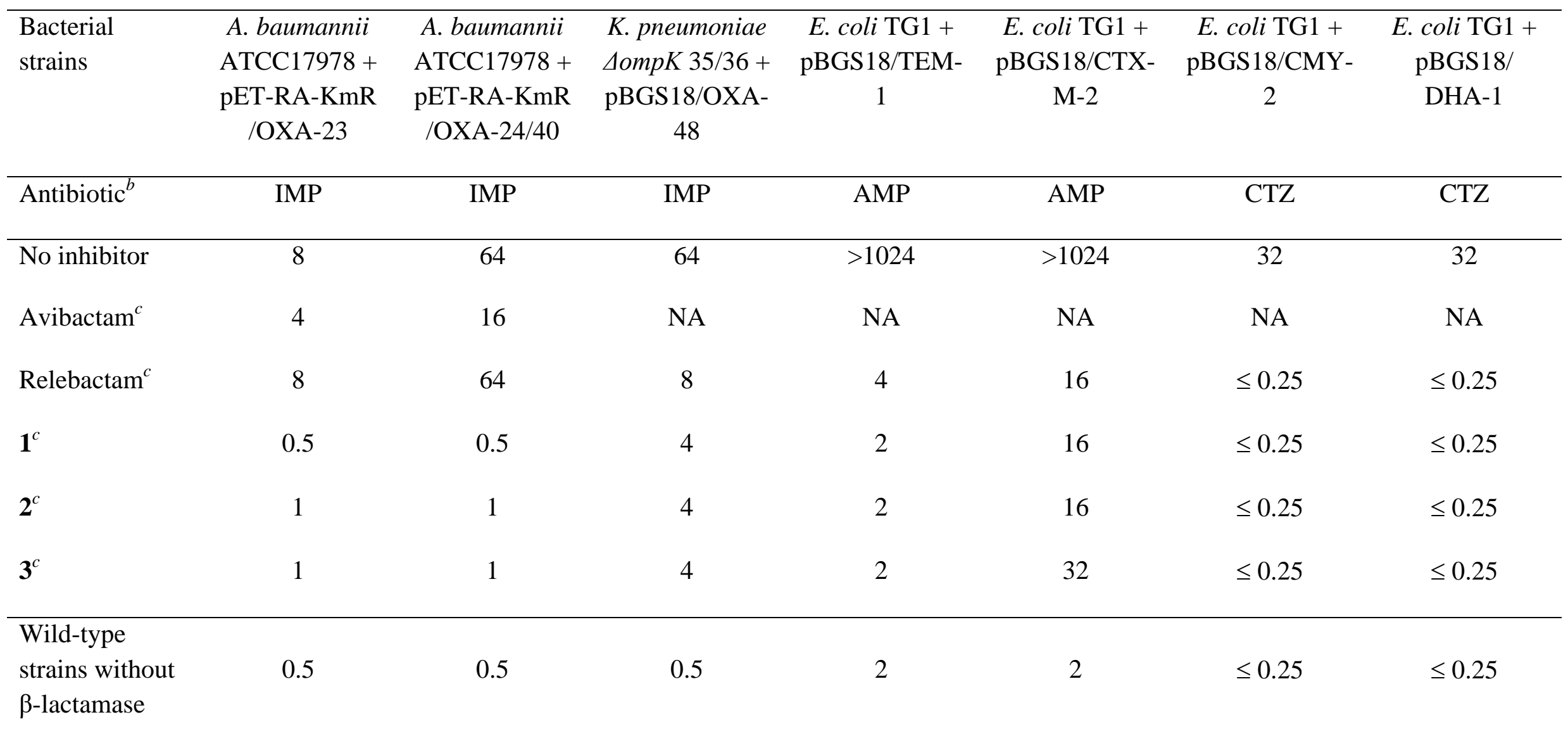

${ }^{a}$ Data represent the means of three independent experiments. Details of the bacterial strains and plasmids used are summarized in Table S3. ${ }^{b} \mathrm{IMP}=$ imipenem; $\mathrm{AMP}=$ ampicillin; $\mathrm{CTZ}=$ ceftazidime. ${ }^{C}$ Inhibitor concentration $=16 \mathrm{mg} / \mathrm{L} . \mathrm{NA}=$ Not applicable (avibactam shows antimicrobial activity against Enterobacterales). 
Table S3. Bacterial strains and plasmids used in Table S2

\begin{tabular}{lll}
\hline Strains & Description & $\begin{array}{l}\text { Reference or } \\
\text { source }\end{array}$ \\
\hline A. baumannii ATCC 17978 & $\begin{array}{l}\text { A. baumannii reference strain completely sequenced. Carbapenem- } \\
\text { susceptible strain (genbank code CP000521.1). }\end{array}$ & ATCC $^{a}$
\end{tabular}

\section{A. baumannii ATCC 17978 A. baumannii ATCC 17978 strain carrying pET-RA+KmR plasmid 1 (pET-RA-KmR+OXA- encoding $b l a_{\mathrm{OXA}-24 / 40}$ gene. Carbapenem-resistant strain. \\ 24/40) \\ A. baumannii ATCC 17978 A. baumannii ATCC 17978 strain carrying pET-RA+KmR plasmid 1 (pET-RA-KmR+OXA-23) encoding bla $a_{\text {OXA-23 }}$ gene. Carbapenem-resistant strain.}
K. pneumoniae
CSUB10R K. pneumoniae strain without porins OmpK35 and
$\triangle$ ompK35/36
OmpK36. $\beta$-Lactam-resistant strain.
K. pneumoniae
$\triangle$ ompK35/36
(pBGS18+OXA-48)
E. coli $\mathrm{TG} 1$
K. pneumoniae $\Delta$ ompK35/36 strain carrying pBGS18 plasmid encoding $b l a_{\mathrm{OXA}-48}$ gene. Increased $\beta$-lactam resistance.
E. coli reference strain completely sequenced. Protease deficient. It ATCC ${ }^{a}$ is suitable for transformation and protein expression. Antimicrobial-susceptible strain (genbank code U00096.3).

E. coli TG1 (pBGS18/TEM- E. coli TG1 strain with cloned pBGS18 plasmid encoding bla $_{T E M-1} 4$ 1) gene. Penicillin-resistant strain.

E. coli TG1 (pBGS18/CTX- E. coli TG1 strain with cloned pBGS18 plasmid encoding bla $a_{\text {CTX-M- }} 4$ $\mathrm{M}-2)$ ${ }_{2}$ gene. $\beta$-Lactam-resistant strain except to carbapenems.
E. coli TG1 E. coli $\mathrm{TG} 1$ strain with cloned pBGS18 plasmid encoding bla $_{\mathrm{CMY}-2} \quad 5$ (pBGS18+CMY-2) gene. $\beta$-Lactam-resistant strain except to carbapenems.
E. coli TG1 (pBGS18+DHA-1)
E. coli TG1 strain with cloned pBGS18 plasmid encoding bla $a_{\mathrm{DHA}-1} \quad 6$ gene. $\beta$-Lactam-resistant strain except to carbapenems.
E. coli BL21
E. coli reference strain completely sequenced. Antimicrobial- susceptible strain (genbank code CP001509.3).
E. coli BL21 (pGEX-6p- 1+OXA-24/40)
E. coli BL21 strain carrying pGEX-6p-1 plasmid encoding bla $a_{O X A-} \quad 1$ $24 / 40$ gene. Strain used for expression and purification of OXA-24/40 $\beta$-lactamase.

$\mathrm{ATCC}^{a}$

\begin{tabular}{lll}
\hline Plasmids & Description & $\begin{array}{l}\text { Reference or } \\
\text { source }\end{array}$ \\
\hline pBGS18 & $\begin{array}{l}\text { Plasmid carrying E. coli replication origin. Encodes kanamycin } \\
\text { resistance. }\end{array}$ & 7 \\
pET-RA-KmR & $\begin{array}{l}\text { Plasmid carrying A. baumannii replication origin. Encodes } \\
\text { rifampicin and kanamycin resistance. }\end{array}$ & 8 \\
pGEX-6P-1 & $\begin{array}{l}\text { Plasmid carrying E. coli replication origin. Bacterial expression } \\
\text { plasmid. GST fusion vector. Encodes ampicillin resistance. }\end{array}$ & GE Healthcare \\
\hline${ }^{a}$ ATCC = American Type Culture Collection
\end{tabular}

${ }^{a}$ ATCC $=$ American Type Culture Collection 


\section{References}

(1) Vázquez-Ucha, J. C.; Maneiro, M.; Martínez-Guitián, M.; Buynak, J. D.; Bethel, C. R.; Bonomo, R. A.; Bou, G.; González-Bello, C.; Beceiro, A. Activity of the $\beta$-Lactamase inhibitor LN-1-255 against carbapenem-hydrolyzing class D $\beta$-lactamases from Acinetobacter baumannii. Antimicrob. Agents Chemother. 2017, 61, e01172-17.

(2) García Sureda, L.; Juan, C.; Doménech-Sánchez, A.; Albertí, S. Role of Klebsiella pneumoniae LamB porin in antimicrobial resistance. Antimicrob. Agents Chemother. 2011, 55, 1803-1805.

(3) Vallejo, J. A.; Martínez-Guitián, M.; Vázquez-Ucha, J. C.; González-Bello, C.; Poza, M.; Buynak, J. D.; Bethel, C. R.; Bonomo, R. A.; Bou, G.; Beceiro, A. LN-1-255, a penicillanic acid sulfone able to inhibit the class D carbapenemase OXA-48. J. Antimicrob. Chemother. 2016, 71, 2171-2180.

(4) Rodríguez D, Maneiro M, Vázquez-Ucha JC, Beceiro A, González-Bello C. 6-Arylmethylidene Penicillin-Based Sulfone Inhibitors for Repurposing Antibiotic Efficiency in Priority Pathogens. $J$. Med. Chem. 2020, 9, 3737-3755.

(5) Pérez-Llarena, F. J.; Vázquez-Ucha, J. C.; Kerff, F.; Zamorano, L.; Miró, E.; Póvoa Cabral, M.; Fleites, A.; Lantero, M.; Martínez-Martínez, L.; Oliver, A.; Galleni, M.; Navarro, F.; Beceiro, A.; Bou, G. Increased antimicrobial resistance in a novel CMY-54 AmpC-type enzyme with a GluLeu $^{217-218}$ insertion in the $\Omega$-loop. Microb. Drug Resist. 2018, 24, 527-533.

(6) Pérez-Llarena, F. J.; Zamorano, L.; Kerff, F.; Beceiro, A.; García, P.; Miró, E.; Larrosa, N.; GómezBertomeu, F.; Méndez, J. A.; González-López, J. J.; Oliver, A.; Galleni, M.; Navarro, F.; Bou, G. Genetic and kinetic characterization of the novel AmpC $\beta$-lactamases DHA- 6 and DHA-7. Antimicrob. Agents Chemother. 2014, 58, 6544-6549.

(7) Spratt, B. G.; Hedge, P. J.; te Heesen, S.; Edelman, A.; Broome-Smith, J. K. Kanamycin-resistant vectors that are analogues of plasmids pUC8, pUC9, pEMBL8 and pEMBL9. Gene 1986, 41, $337-342$.

(8) Aranda, J.; Poza, M.; Pardo, B. G.; Rumbo, S.; Rumbo, C.; Parreira, J. R.; Rodríguez-Velo, P.; Bou, G. A rapid and simple method for constructing stable mutants of Acinetobacter baumannii. BMC Microbiol. 2010, 10, 279. 